\title{
A Technique for Simulating Strong Ground Motion Using Hybrid Green's Function
}

\author{
by Katsuhiro Kamae, Kojiro Irikura, and Arben Pitarka
}

\begin{abstract}
A method for simulating strong ground motion for a large earthquake based on synthetic Green's function is presented. We use the synthetic motions of a small event as Green's functions instead of observed records of small events. Ground motions from small events are calculated using a hybrid scheme combining deterministic and stochastic approaches. The long-period motions from the small events are deterministically calculated using the 3D finite-difference method, whereas the high-frequency motions from them are stochastically simulated using Boore's method. The small-event motions are synthesized summing the long-period and short-period motions after passing them through a pair of matched filters to follow the omega-squared source model. We call the resultant time series "hybrid Green's functions" (HGF). Ground motions from a large earthquake are simulated by following the empirical Green's function (EGF) method. We demonstrate the effectiveness of the method at simulating ground motion from the 1995 Hyogo-ken Nanbu earthquake $(M w 6.9)$.
\end{abstract}

\section{Introduction}

Studies of the ground motion from the 1994 Northridge, California, earthquake and the 1995 Hyogo-ken Nanbu, Japan, earthquake have shown that the combined effects of the source process and wave propagation path may cause largeamplitude ground motions at particular areas that cannot be predicted by simplified $1 \mathrm{D}$ or purely stochastic modeling techniques (e.g., Graves, 1995; Pitarka and Irikura, 1996; Hartzell et al., 1996; Kawase, 1996; Motosaka and Nagano, 1996; Pitarka et al., 1997, 1998). The empirical Green's function (EGF) method, originally proposed by Hartzell (1978) and then developed by many researchers (e.g., Irikura, 1986), is one of the simplest techniques that accounts for such effects. Compared with other deterministic techniques, it has the advantage of not requiring to compute numerically the propagation and local site effects (Kamae $e t$ al., 1998; Kamae and Irikura, 1998). Its main limitation is that it can be applied only in cases where appropriate records of small events in the source area, which are considered as Green's functions, are available. Unfortunately, it is rare to have good records of such small events, especially in the source area of a future large earthquake.

As an alternative way to avoid this limitation, we propose the use of synthetic Green's functions that are calculated based on a hybrid scheme that combines different methods for calculating the low- and high-frequency part of the Green's functions. The low-frequency part (in general, less than $1 \mathrm{~Hz}$ ) is calculated by a 3D finite-difference method assuming a point source located in the source area and using a velocity model of the irregular geological structure. The high-frequency part (in general, higher than $1 \mathrm{~Hz}$ ) is calculated using the stochastic simulation technique of Boore (1983). The low- and the high-frequency motions are corrected for the effect of the surface layers not included in each motion. The synthetic Green's function is then calculated by combining the low- and high-frequency part of the motion, as explained in the following section. We call this the resultant "hybrid Green's function" (HGF). Finally, strong ground motions from a large earthquake are obtained by the summation of the HGFs following the EGF method. Our hybrid scheme is different from the ones proposed by Heaton et al. (1995) and Saikia (1993), which are based on adopted empirical high-frequency Green's functions. We have checked the capability of the proposed method by simulating the near-source ground motions from the $1995 \mathrm{Hy}-$ ogo-ken Nanbu earthquake ( $M w 6.9)$.

\section{Method}

The flow chart of the HGF method is presented in Figure 1. First, we simulate high-frequency ground motion $f>1$ $\mathrm{Hz}$ ) from a hypothetical small event located in the fault plane of the target earthquake using the stochastic simulation technique of Boore (1983), assuming a point source. We can apply his method to the simulation of ground motion from the small event because the source size of the event is small enough to neglect the rupture propagation effect. By using 


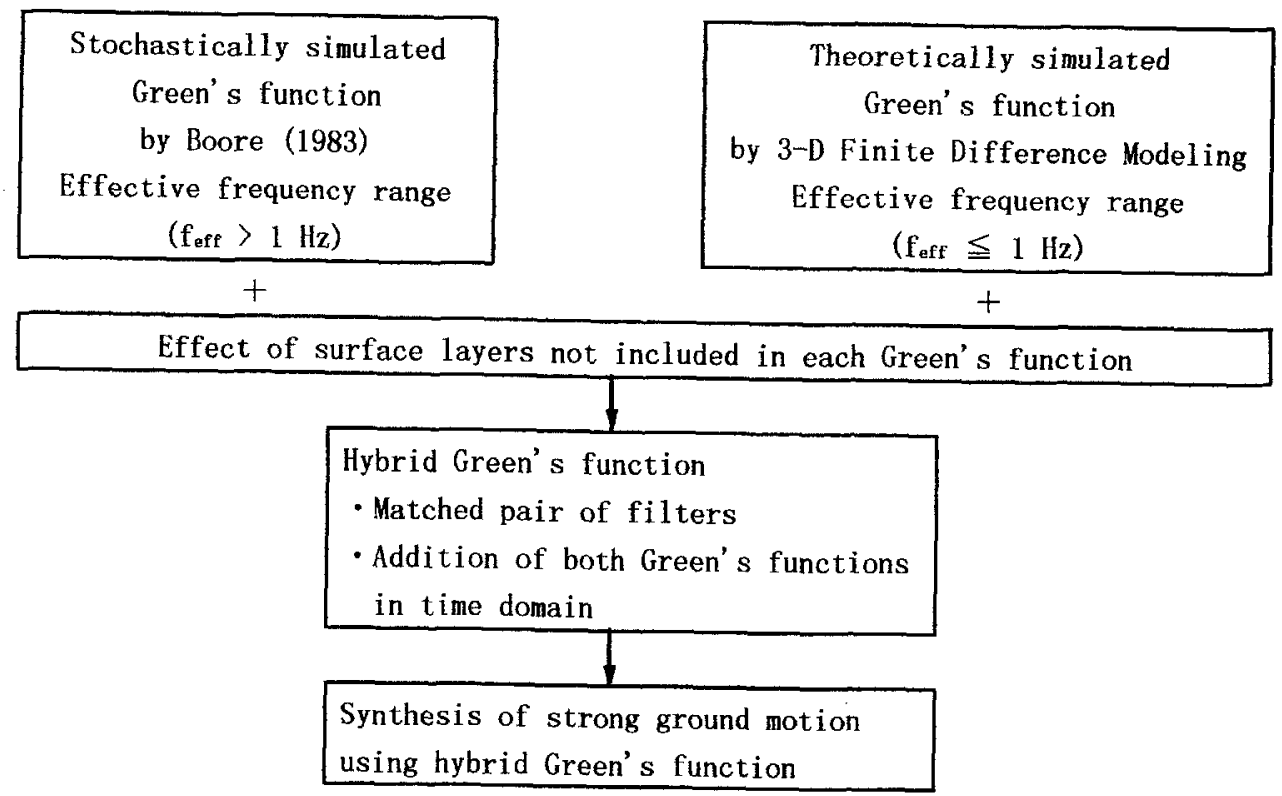

Figure 1. Flow chart of simulation methodology of strong ground motions using a hybrid Green's function.

Boore's method, the high-frequency part of the simulated Green's function has an acceleration amplitude spectrum that follows the $\omega^{-2}$ model with the high-frequency cutoff, $f_{\max }=15 \mathrm{~Hz}$. We consider a frequency-dependent $Q$ value, derived from obtained ground motions, to take into account the effect of the wave propagation in the acceleration spectrum. Second, we calculate the low-frequency part of the Green's function $(f<1 \mathrm{~Hz})$ using the 3D finite-difference method, assuming a point source and adopting a $3 \mathrm{D}$ velocity model of the heterogeneous structure. We apply a correction for the effect of the local surface layers not included in Boore's method as well as the 3D calculation. After that, we calculate the HGF by combining both the low- and highfrequency waves in the time domain. A matched pair of filters is then used to remove the low- (less than $1 \mathrm{~Hz}$ ) and high-frequency content (more than $1 \mathrm{~Hz}$ ) from the stochastically simulated motion and the finite-difference synthetic motion, respectively. Finally, strong ground motions from the large earthquake are simulated by the summation of the HGFs following the EGF method of Irikura (1986).

We simply outline the procedure of Irikura (1986) formulated to match the scaling of source spectra as well as the scaling of source parameters, in which both large and small events follow the $\omega^{-2}$ model. The ground motions from a large event are expressed as a superposition of the records of small events as follows:

$$
U(t)=C \sum_{i=1}^{N} \sum_{j=1}^{N} \frac{r}{r_{i j}} F\left(t-t_{i j}\right) * u(t)
$$

where

$$
\begin{gathered}
t_{i j}=\frac{r_{i j}-r_{0}}{\beta}+\frac{\xi_{i j}}{V_{R}} \\
F(t)=\delta(t)+\frac{1}{n^{\prime}} \sum_{k=1}^{(N-1)^{n \prime}} \delta\left[t-(k-1) \frac{\tau}{(N-1) n^{\prime}}\right]
\end{gathered}
$$

and $U(t)$ and $u(t)$ are the ground motion for a large event and the observed record of a small event used as the EGF, respectively. The terms $r, r_{i j}$, and $r_{0}$ are the respective distances from the site to the hypocenter of a small event, from the site to the $(i, j)$ subfault, and from the site to the starting point of rupture on the fault plane of the large event. $\xi_{i j}$ is the distance between the starting point and ( $\mathrm{i}, \mathrm{j})$ sub-fault. $\beta$ is the shear-wave velocity, $V_{R}$ the rupture velocity, and $\tau$ the rise time of the large event. $C$ is the stress drop ratio for the large and small events, and $n^{\prime}$ is an arbitrary integer number to shift the artificial periodicity to a frequency higher than that of interest. $N$, a scaling parameter, is obtained from equation (4):

$$
N=\left(\frac{M_{0 t}}{C M_{0 s}}\right)^{1 / 3}
$$

where $M_{0 t}$ and $M_{0 s}$ are the seismic moments for the large and small events, respectively.

This formulation can be easily extended to cases where the target event consists of multiple shocks, each of which follows the $\omega^{-2}$ model. The omega-squared model used here means that the source displacement spectrum has a flat level at low frequencies and an omega-squared decay at high frequencies beyond a corner frequency but not always a con- 

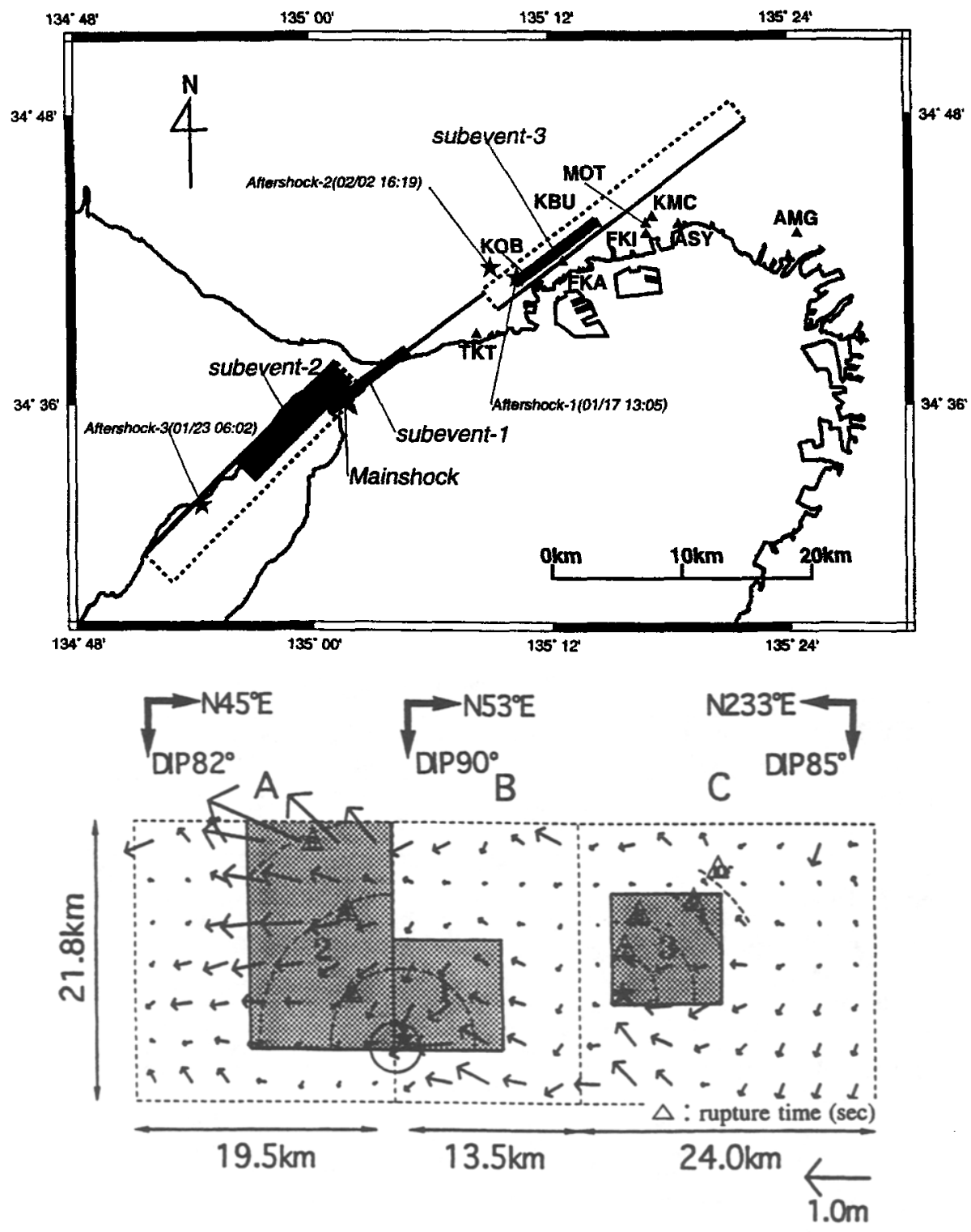

Figure 2. Source model consisting of three asperities (subevents) estimated from forward modeling using the empirical Green's function method (Kamae and Irikura, 1998). Our model (hatched) is superimposed on the model of Sekiguchi et al. (1996) in lower figure. Source parameters for each subevent are summarized in Table 1. We assumed that ground motions are generated only from the hatched zone on the fault plane. The respective number of subfaults $(N)$ calculated from equation (4) according to the source parameters of each subevent and $M 4.7$ small event is 5 for subevents 1 and 3 , and 9 for subevent 2 .

stant stress drop between large and small events. We use formulation (1) by replacing the records of small events as EGFs with the calculated HGFs.

\section{Application to Modeling Ground Motion from the 1995 Hyogo-ken Nanbu Earthquake}

The 1995 Hyogo-ken Nanbu earthquake is one of the most destructive earthquakes of the twentieth century in Japan. The heavily damaged zone in the Kobe area extends along a narrow belt approximately $30 \mathrm{~km}$ long and $1 \mathrm{~km}$ wide, offset by about $1 \mathrm{~km}$ southeast of the causative faults. Based on 3D simulations of the near-fault ground motion, Pitarka et al. (1998) concluded that such damaged band area was caused by the amplification of the ground motion due to the coupling of the forward rupture directivity effect and the basin edge effects. Their simulation of long-period ground motions $(>1 \mathrm{sec})$ uses a simplified velocity model that does not account for the soft surface-layer effect. Consequently, the peak amplitude of the simulated ground motion is lower than the recorded one at sites within the Osaka basin. Synthetic Green's function calculated with the proposed hybrid scheme can better represent the effect of the surface layers and consequently improve the result obtained by a purely deterministic approach. In this study, we simulate near-source ground motions using the HGF method and compare them with ground-motion records at several stations TKT (Nakamura et al., 1996), KOB, KBU, MOT (Kagawa et al., 1996), FKI, and ASY in the Kobe area shown in Figure 2.

\section{Source Model}

Many researchers have determined the rupture model of the 1995 Hyogo-ken Nanbu earthquake (e.g., Sekiguchi et al., 1996; Wald, 1996; Yoshida et al., 1996; Ide and Takeo, 
1996; Horikawa et al., 1996). All these models have been obtained by inverting long-period ground-motion data and/or geodetic data. Consequently, they are not always appropriate for estimating high-frequency near-source strong ground motions. Kamae and Irikura (1998) proposed a source model, in which the slip was concentrated within three regions on the fault to represent the main asperities found by source inversion analysis. The stress drop is assumed to be constant within the asperities and zero in the other regions on the fault. Based on the source model, they simulated the broadband-frequency ground motions from the mainshock using the EGF method. In this study, we use the same source representation (Fig. 2). The source parameters for each subevent are summarized in Table 1.

\section{Hybrid Green's Function Calculation}

\section{Low-Frequency Motion}

Hybrid Green's functions are calculated for three point sources located at the center of the three asperities on the fault assuming a magnitude 4.7 for each of them. This magnitude is the same as the one adopted for the aftershock used in another simulation of strong ground motion in Kobe that was based on the EGF method (Kamae and Irikura, 1998). We used a bell-shaped source-time function, $S(t)=[1.0-$ $\left.\cos \left(2 \pi t / T_{0}\right)\right] / 2 T_{0}$, with a duration $T_{0}=0.12 \mathrm{sec}$, and the source parameters summarized in Table 2 . For each point source, we assumed a pure right-lateral strike-slip mechanism with the strike and dip corresponding to each subfault. The basin velocity model used in the 3D finite-difference calculations includes a single sedimentary layer with the shear-wave velocity $V s=0.8 \mathrm{~km} / \mathrm{sec}$, compressional wave velocity $V p=1.6 \mathrm{~km} / \mathrm{sec}$, density $\rho=2.1 \mathrm{~g} / \mathrm{cm}^{3}$, constant attenuation factor $Q=80$, and a background $1 \mathrm{D}$ velocity model (Table 3). Figure 3 shows the region considered in the 3D modeling including the Kobe city area and a part of Awaji Island, and the fault trace. The underground bedrock topography is depicted in Figure 4. The Green's functions are calculated at sites shown in Figure 3 and Table 4. The selected sites are stations that recorded the near-fault ground motion from the mainshock except for FKI and ASY. These two temporary stations were installed after the mainshock during an array observation of ground-motion amplification in the heavily damaged zone. Aftershock ground motions recorded during the observation suggest a large amplification due to the basin edge and local site effects, especially at FKI and ASY (Iwata et al., 1996; Pitarka et al., 1996, 1997). As shown later, we use these two sites to compare the results obtained by the new technique and the EGF method that has been done in Kamae and Irikura (1998). Figure 5 shows the finite-difference velocity ground motions at periods of $1 \mathrm{sec}$ and longer for the first, second, and third small event, respectively. The waveforms at $\mathrm{KBU}$, which is a softrock site outside the basin, are very simple. They represent mainly the source process. In comparison to the wave-
Table 1

Source Parameters for Three Subevents

\begin{tabular}{lcccc}
\hline & $\begin{array}{c}M_{0} \\
\left(\mathrm{~N}^{*}\right)\end{array}$ & $\begin{array}{c}L \times W \\
(\mathrm{~km} \times \mathrm{km})\end{array}$ & $\begin{array}{c}\Delta \sigma \\
(\text { bars })\end{array}$ & $\begin{array}{c}\text { Depth of Top } \\
(\mathrm{km})\end{array}$ \\
\hline Subevent 1 & $3.4 \times 10^{18}$ & $8 \times 8$ & 163 & 8 \\
Subevent 2 & $1.0 \times 10^{19}$ & $11 \times 16$ & 86 & 0 \\
Subevent 3 & $1.8 \times 10^{18}$ & $8 \times 8$ & 86 & 5 \\
\hline
\end{tabular}

Table 2

Source Parameters for $M 4.7$ Small Event

\begin{tabular}{lc}
\hline Seismic moment $\left(\mathrm{N}^{*} \mathrm{~m}\right)$ & $7.1 \times 10^{15}$ \\
Corner frequency $(\mathrm{Hz})$ & 1.5 \\
Fault area $\left(\mathrm{km}^{2}\right)$ & 2.4 \\
Stress drop (bars) & 46 \\
Rise time (sec) & 0.12 \\
\hline
\end{tabular}

Table 3

Background Velocity Model

\begin{tabular}{ccccc}
\hline $\begin{array}{c}\text { Depth } \\
(\mathrm{km})\end{array}$ & $\begin{array}{c}\text { S-Wave Velocity } \\
(\mathrm{km} / \mathrm{sec})\end{array}$ & $\begin{array}{c}P \text {-Wave Velocity } \\
(\mathrm{km} / \mathrm{sec})\end{array}$ & $\begin{array}{c}\text { Density } \\
\left(\mathrm{gm} / \mathrm{cm}^{3}\right)\end{array}$ & $Q$ value \\
\hline \multirow{2}{*}{4.0} & 3.2 & 5.5 & 2.6 & 300 \\
& 3.46 & 6.0 & 2.7 & 400 \\
\hline
\end{tabular}

Table 4

Station Locations

\begin{tabular}{cccl}
\hline $\begin{array}{c}\text { Station } \\
\text { Name }\end{array}$ & $\begin{array}{c}\text { Lat. } \\
(\mathrm{deg})\end{array}$ & $\begin{array}{c}\text { Long. } \\
(\mathrm{deg})\end{array}$ & $\begin{array}{c}\text { Geological } \\
\text { Condition }\end{array}$ \\
\hline TKT & 34.649 & 135.138 & Alluvium \\
KOB & 34.688 & 135.180 & Diluvium \\
KBU & 34.725 & 135.240 & Soft rock \\
MOT & 34.725 & 135.281 & Alluvium \\
FKI & 34.718 & 135.281 & Alluvium \\
ASY & 34.724 & 135.309 & Alluvium \\
\hline
\end{tabular}

forms at KBU, the ground motions simulated at the sedimentary sites are characterized by complex waveforms influenced by the basin edge effects.

In order to check the quality of the calculated low-frequency Green's functions, we computed long-period ground motion obtained by the summation of the synthetic Green's function for the source model (Fig. 2) by Kamae and Irikura (1998) and compared it with recorded mainshock ground motion, bandpass filtered at 0.2 to $1.0 \mathrm{~Hz}$. Figure 6 shows the comparison at $\mathrm{KBU}, \mathrm{KOB}$, and MOT. The original velocity seismograms at MOT were clipped in amplitudes larger than $40 \mathrm{~cm} / \mathrm{sec}$. Therefore, we used the restored seismograms based on the saturation characteristics of the sensor (Kagawa et al., 1996). The synthetic motion agrees well with the observed one at KBU. The peak amplitude of the synthetics is underestimated at KOB and MOT by a factor of 2 . This discrepancy might be caused by the adopted 3D veloc- 


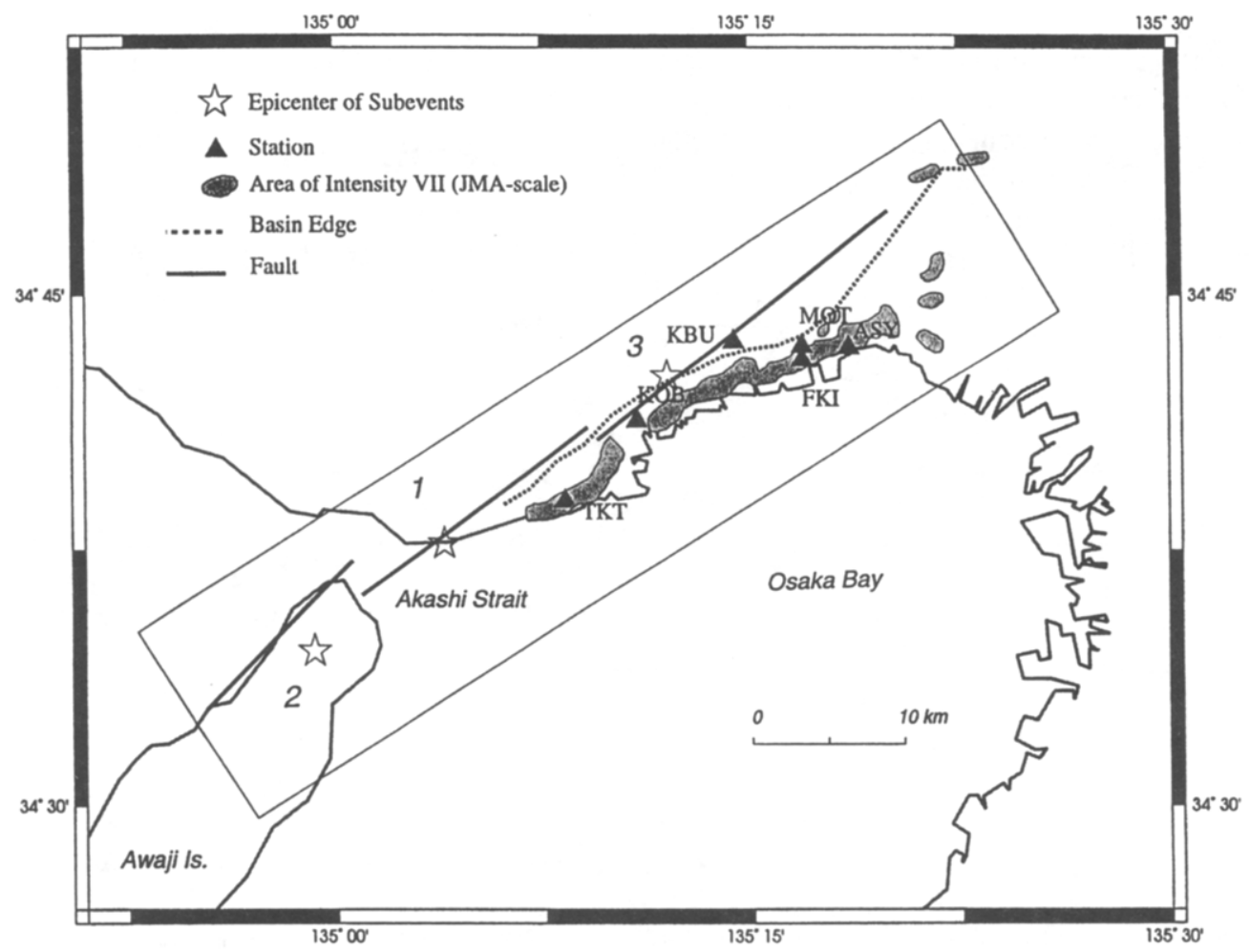

Figure 3. Map of the Kobe area and station locations. The rectangle shows the aerial extention of the basin model used in this study. Also shown are the locations of the heavily damaged zone [intensity 7, JMA scale, digitized data from Koketsu (1997)], and the epicenters of three hypothetical $M 4.7$ small events (star symbol). Solid triangles indicate the location of mainshock observation stations (TKT, KOB, KBU, and MOT) and aftershock observation stations (FKI and ASY). Solid lines show the surface intersections of the causative faults determined by the strong-motion data (Sekiguchi et al., 1996).

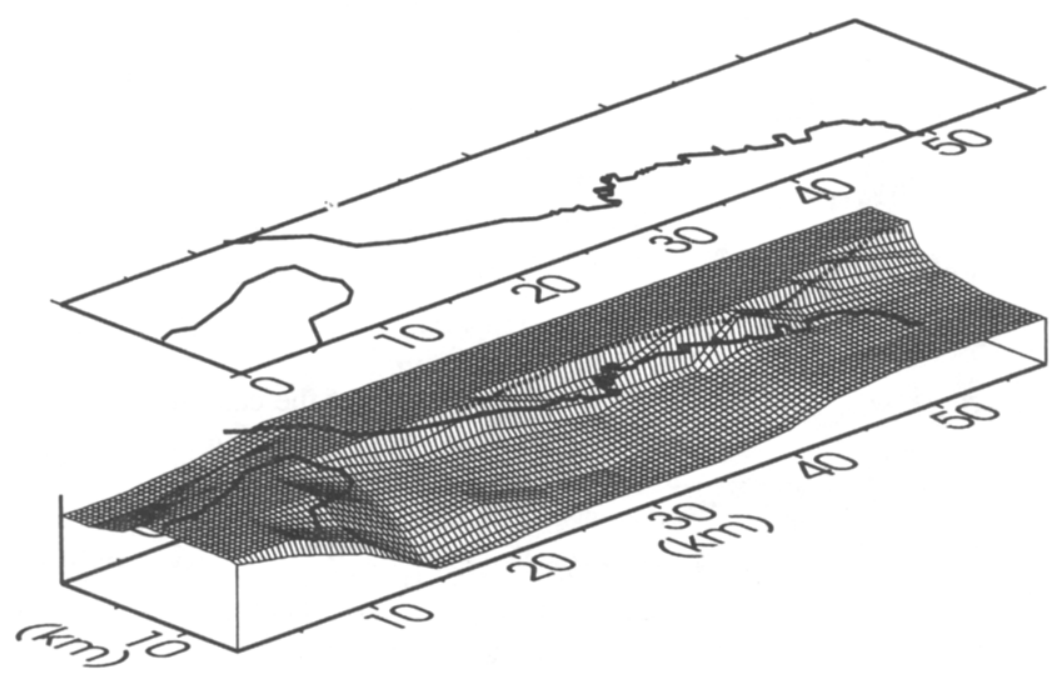

Figure 4. The bedrock topography in the Kobe area used in the 3D finite-difference modeling (Pitarka et al., 1997b). ity model that does not include the soft surface layers in the basin. To include the amplification due to the surface sedimentary layers into the Green's function, we correct them using the spectral ratio between the transfer function calculated for the one-dimensional velocity model (Table 5) of the structure beneath each station and the one for the corresponding one-dimensional profile of the 3D velocity model, assuming a vertical incidence of $S$ waves. Figure 7 shows the comparison between the synthetic velocity seismograms using low-frequency Green's functions, corrected 
Fault Normal

(a)

(b)

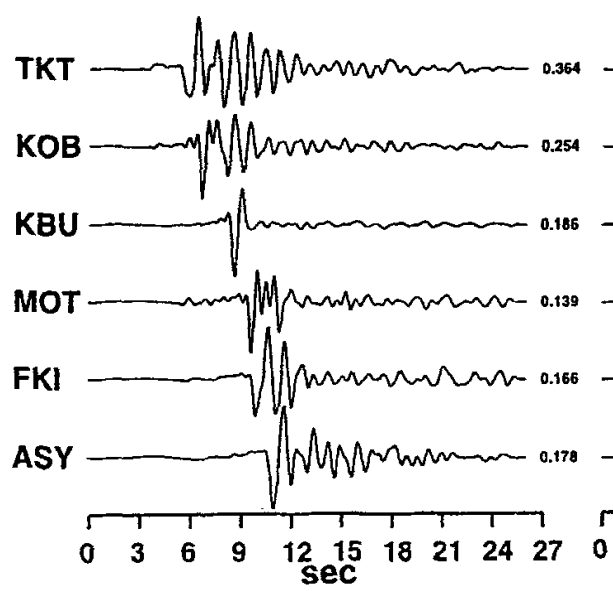

Fault Parallel

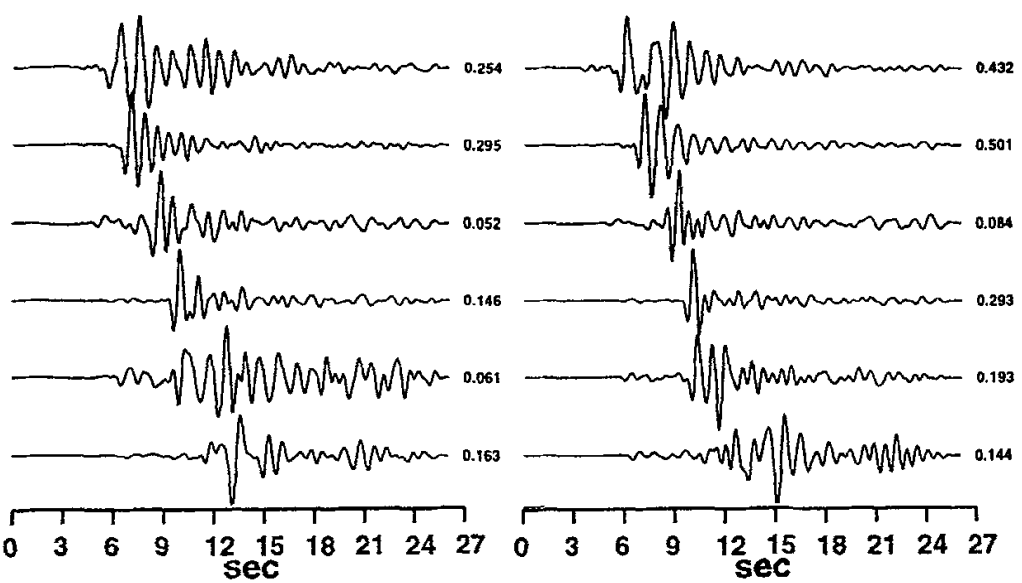

(c)
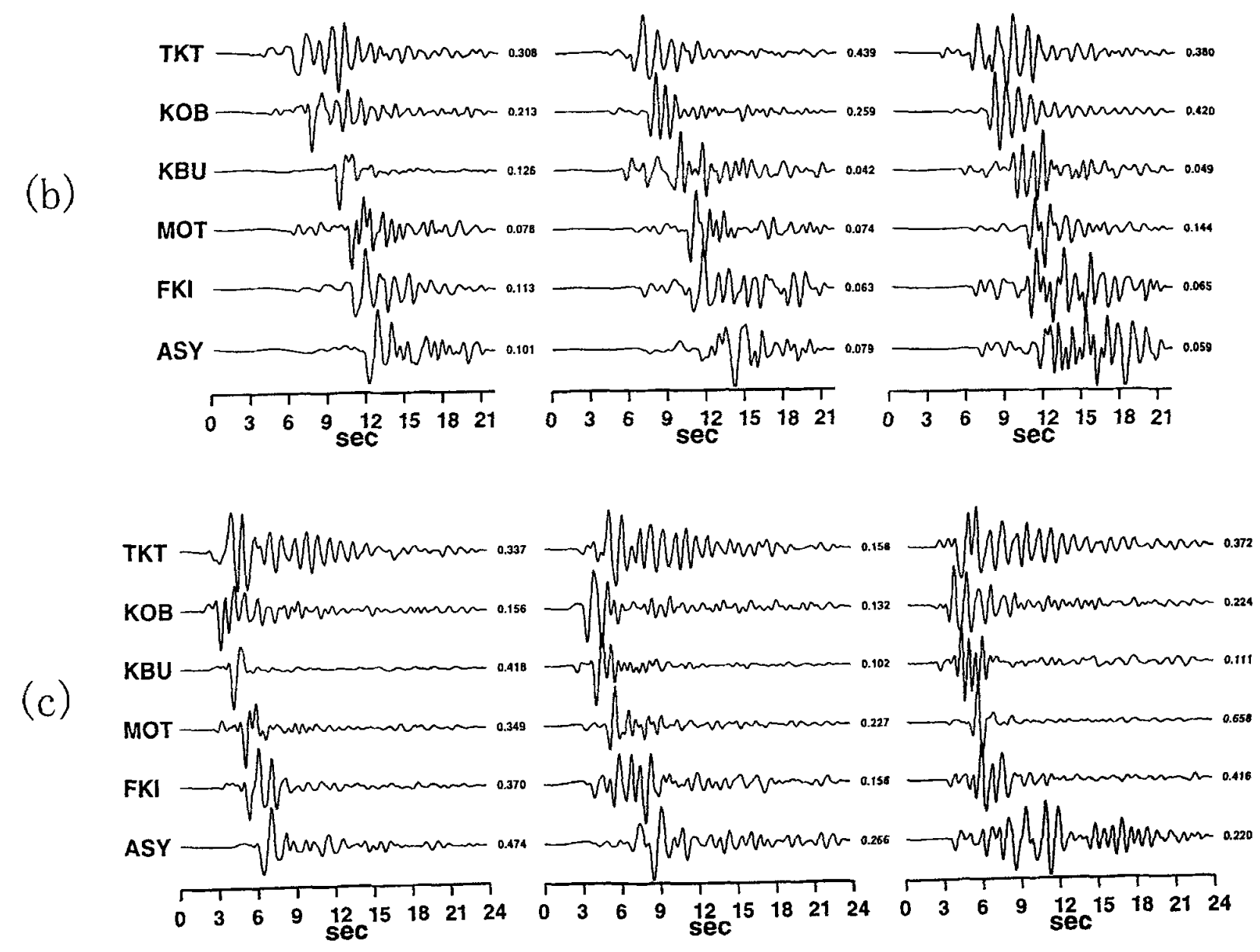

Figure 5. Finite-difference velocity seismograms from three hypothetical $M 4.7$ small events: (a) number 1 small event, (b) number 2 small event, and (c) number 3 small event. 


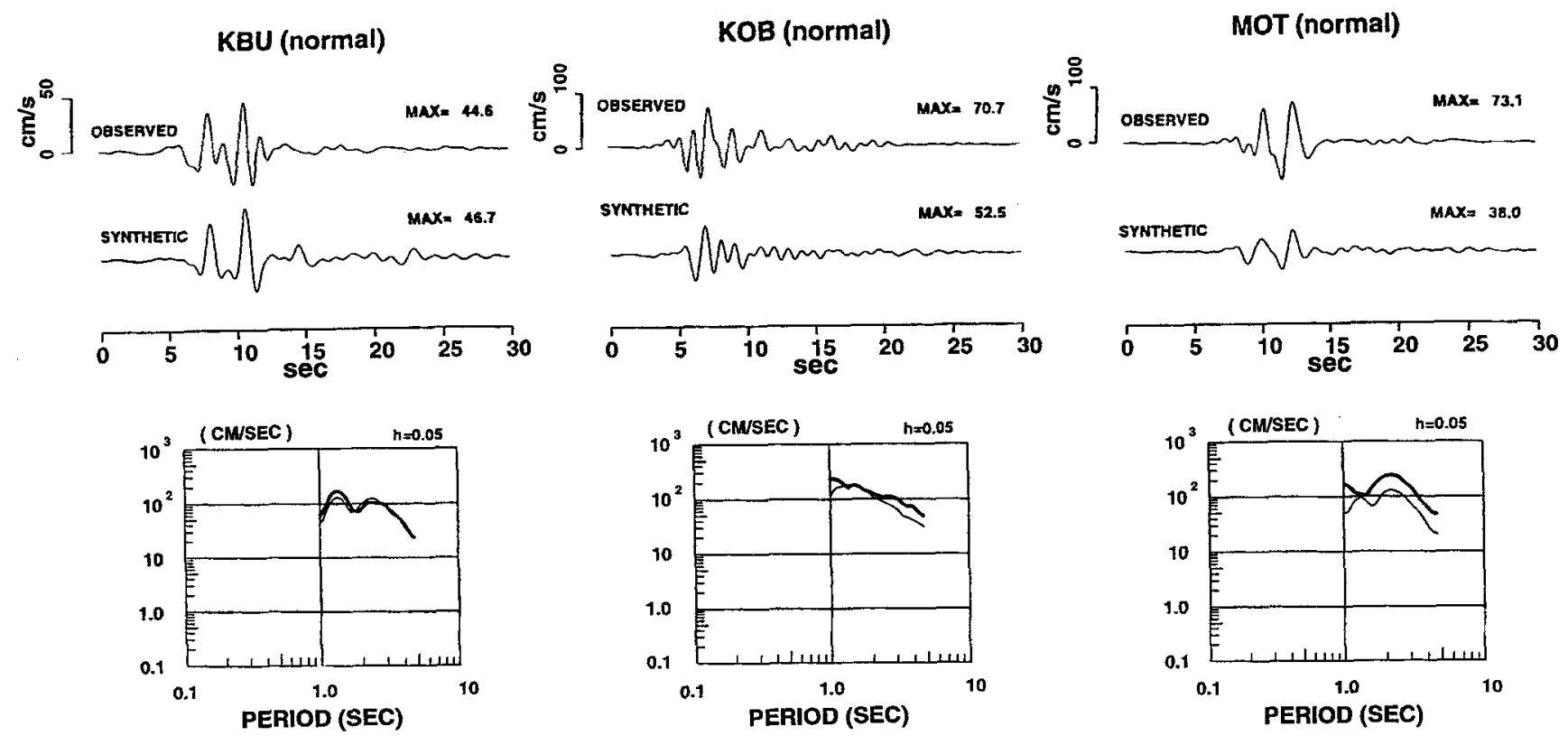

Figure 6. Comparison between the fault normal synthetic velocity seismogram using a low-frequency Green's function and the observed one from the mainshock at $\mathrm{KBU}, \mathrm{KOB}$, and MOT. Each lower panel shows the corresponding pseudo-velocity response spectra (5\% damping). The heavy solid lines are observed spectra, and the light solid lines are the synthetics. The seismograms are bandpass filtered between 0.2 and $1.0 \mathrm{~Hz}$.

Table 5

One-Dimensional Velocity Models

\begin{tabular}{|c|c|c|c|c|c|c|c|}
\hline \multicolumn{4}{|c|}{ Site: TKT } & \multicolumn{4}{|c|}{ Site: FKI, ASY } \\
\hline $\begin{array}{l}\text { Depth } \\
\text { (m) }\end{array}$ & $\begin{array}{c}V_{s} \\
(\mathrm{~m} / \mathrm{sec}) \\
\end{array}$ & $\begin{array}{l}\text { Density } \\
\left(\mathrm{g} / \mathrm{cm}^{3}\right)\end{array}$ & $Q s$ & $\begin{array}{l}\text { Depth } \\
\text { (m) }\end{array}$ & $\begin{array}{c}V_{s} \\
(\mathrm{~m} / \mathrm{sec})\end{array}$ & $\begin{array}{l}\text { Density } \\
\left(\mathrm{g} / \mathrm{cm}^{3}\right)\end{array}$ & $Q s$ \\
\hline 24.0 & 200 & 1.8 & 30 & 10.0 & 150 & 1.8 & 10 \\
\hline 34.0 & 300 & 1.9 & 50 & 45.0 & 300 & 1.9 & 50 \\
\hline 54.0 & 350 & 1.9 & 50 & 100.0 & 450 & 1.9 & 80 \\
\hline 150.0 & 500 & 2.0 & 80 & 250.0 & 550 & 2.0 & 80 \\
\hline 350.0 & 650 & 2.0 & 80 & 550.0 & 650 & 2.0 & 80 \\
\hline \multirow[t]{2}{*}{1250.0} & 1100 & 2.2 & 170 & 1150.0 & 1100 & 2.2 & 170 \\
\hline & 3200 & 2.5 & 300 & & 3200 & 2.5 & 300 \\
\hline \multicolumn{4}{|c|}{ Site: KOB } & \multicolumn{4}{|c|}{ Site: MOT } \\
\hline 10.0 & 300 & 1.8 & 30 & 10.0 & 240 & 1.8 & 30 \\
\hline 60.0 & 450 & 1.9 & 80 & 35.0 & 300 & 1.9 & 50 \\
\hline 200.0 & 550 & 2.0 & 80 & 50.0 & 450 & 1.9 & 80 \\
\hline 400.0 & 650 & 2.0 & 80 & 150.0 & 500 & 2.0 & 80 \\
\hline \multirow[t]{3}{*}{600.0} & 1100 & 2.2 & 170 & 300.0 & 650 & 2.0 & 80 \\
\hline & 3200 & 2.5 & 300 & 600.0 & 1100 & 2.2 & 170 \\
\hline & & & & & 3200 & 2.5 & 300 \\
\hline
\end{tabular}

for the surface layer effect, and the observed ones $(0.2$ to $1.0 \mathrm{~Hz}$ ) at KOB and MOT. The good fit between the synthetic and the observed long-period ground motion suggests that the adopted source model and the calculated low-frequency Green's functions can be used to simulate the long period from the mainshock ground motion at other sites in the basin. The slight discrepancy at 1 to $2 \mathrm{sec}$ shows the necessity of improvement of the adopted 3D basin velocity model.

\section{High-Frequency Motion}

Next, we simulate the high-frequency part of Green's functions based on the stochastic simulation technique proposed by Boore (1983). The magnitude and the source parameters of the corresponding small event are the same as the ones for the low-frequency Green's function previously described (see Table 2). To take into consideration the propagation path effect, we use a frequency-dependent $Q$ value $\left(Q s=33 f^{0.85}\right)$ estimated by Tai et al. (1996) using aftershock records at sites in our target area. We generated 20 high-frequency Green's functions using a pseudo-random generator of white noise. The Green's functions were corrected for the local site effect by using the 1D transfer functions at each sediment site. The 1D velocity models are based on the available geotechnical information and shallow bore-hole data (Table 5).

\section{Simulation of Near-Source Ground Motion from the Mainshock}

We followed the proposed procedure to calculate HGFs for the three subevents of the mainshock. The entire procedure for estimating the acceleration of HGF is schematically shown in Figure 8. The synthetic ground motions from the mainshock are generated at each site by summing the HGF for each subevent assuming that their source spectrum obeys the omega-square model (Irikura, 1986). For each station, in Figure 9, we show the comparison between the observed and 

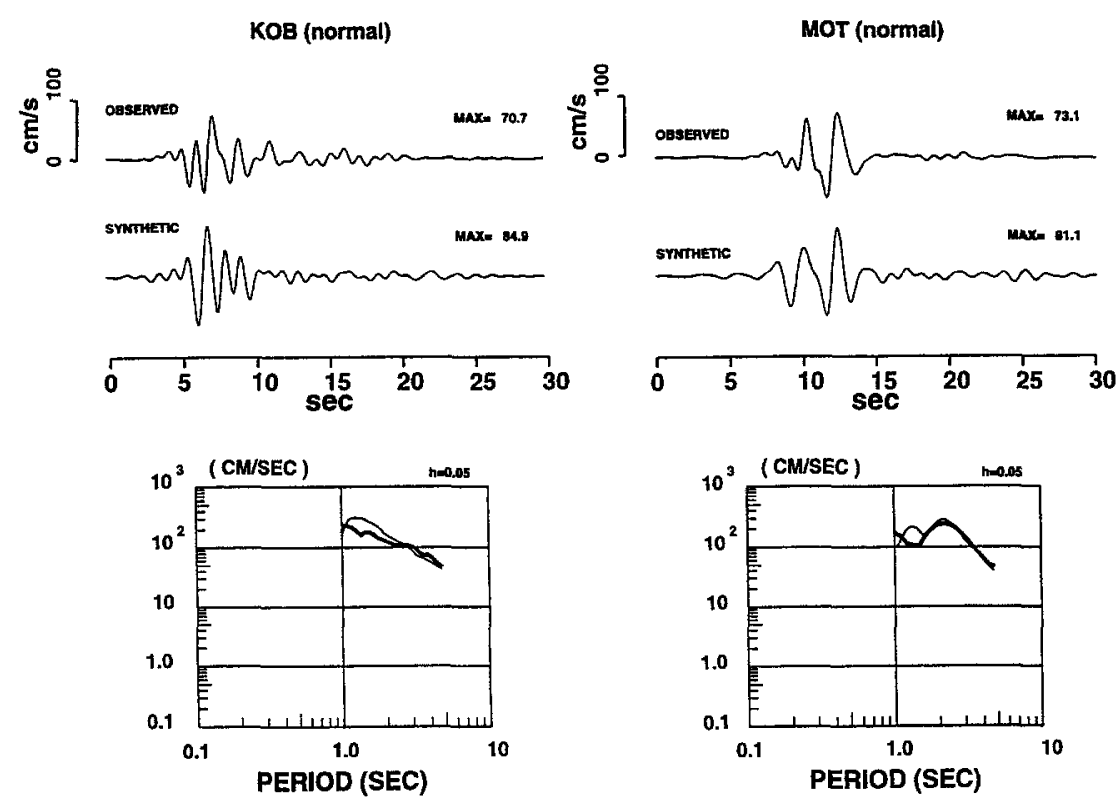

(a)
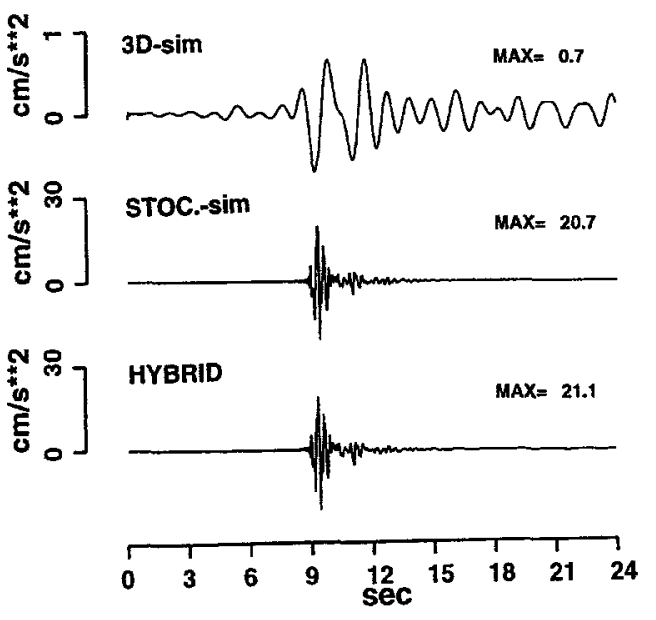

(c)
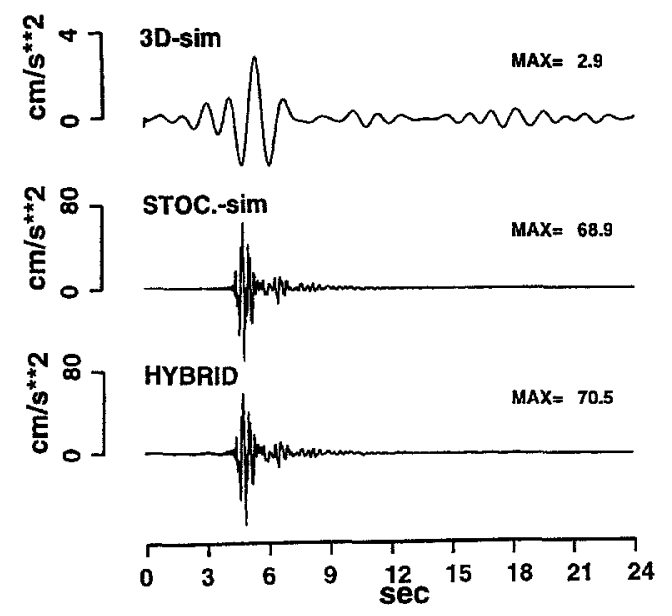

(b)
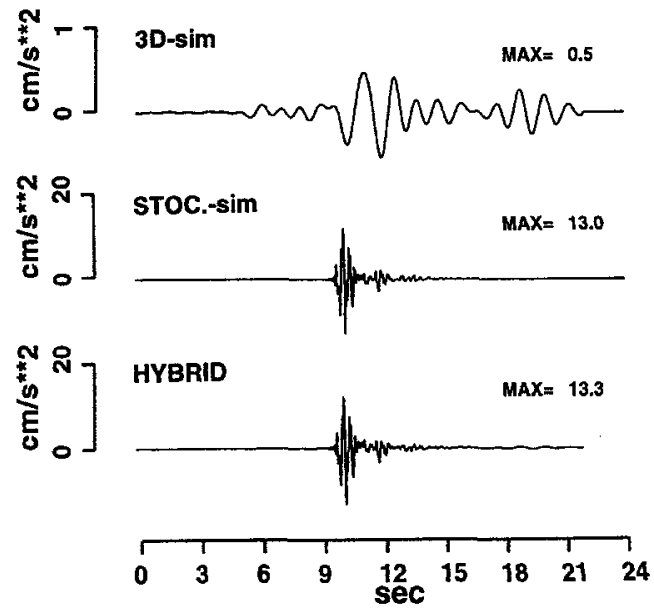

Figure 8. An example of the entire procedure used for estimating the acceleration of hybrid Green's function. (a), (b), and (c) show the Green's functions from, respectively, number 1,2 , and 3 hypothetical small events at MOT station. In each figure, "3D-sim" shows the corrected low-frequency Green's function, bandpass filtered between 0.2 and $1.0 \mathrm{~Hz}$; "STOC-sim" shows the corrected high-frequency Green's function, bandpass filtered between 1.0 and $10 \mathrm{~Hz}$; and "HYBRID" shows the hybrid Green's function obtained by summing "3D-sim" and "STOC-sim" seismograms. 

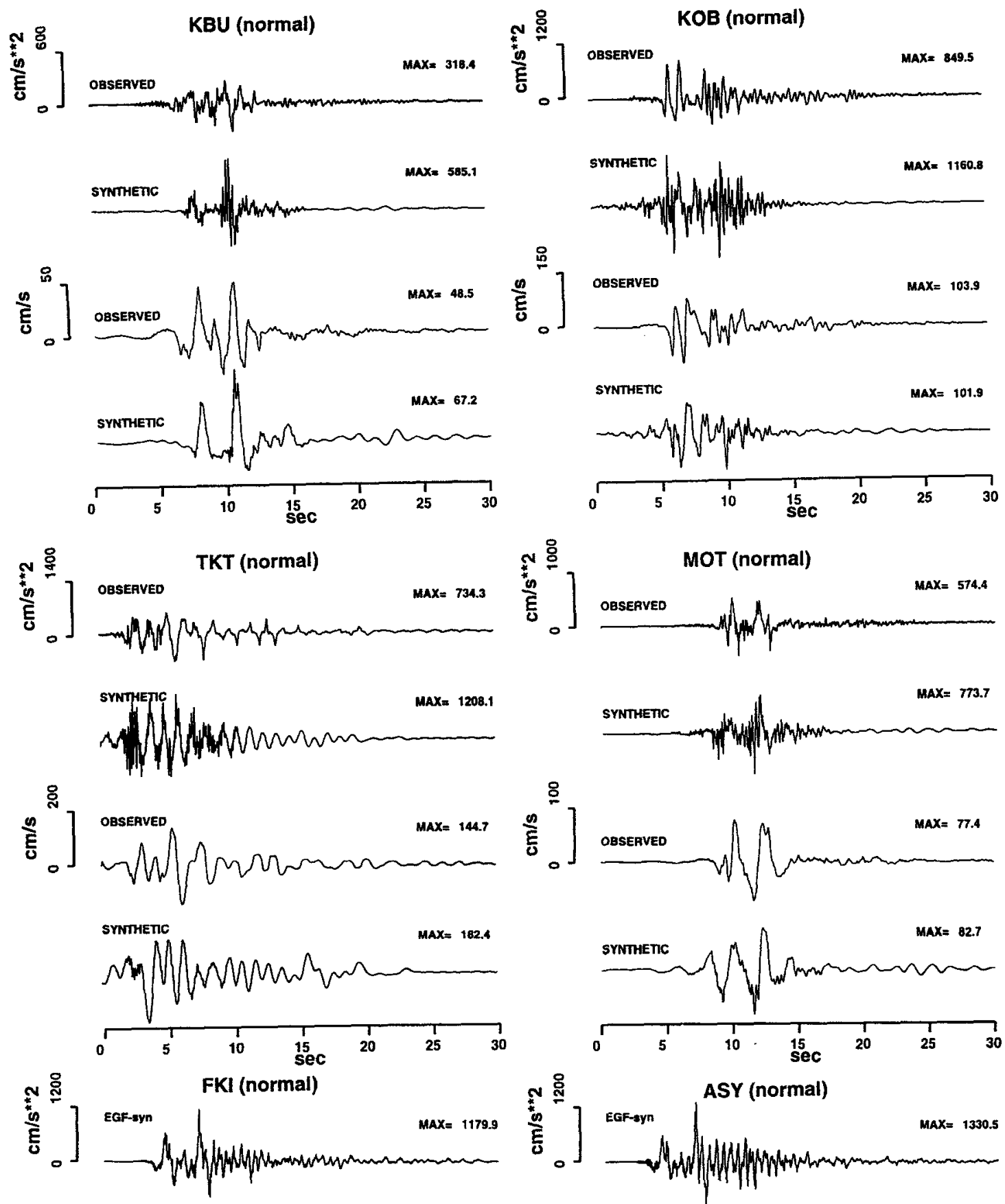

$\operatorname{MAX}=1030.7$ SYNTHETiC
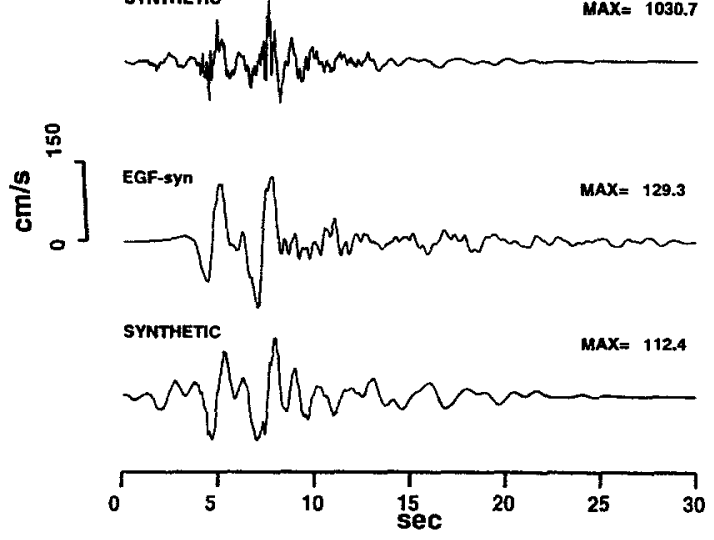
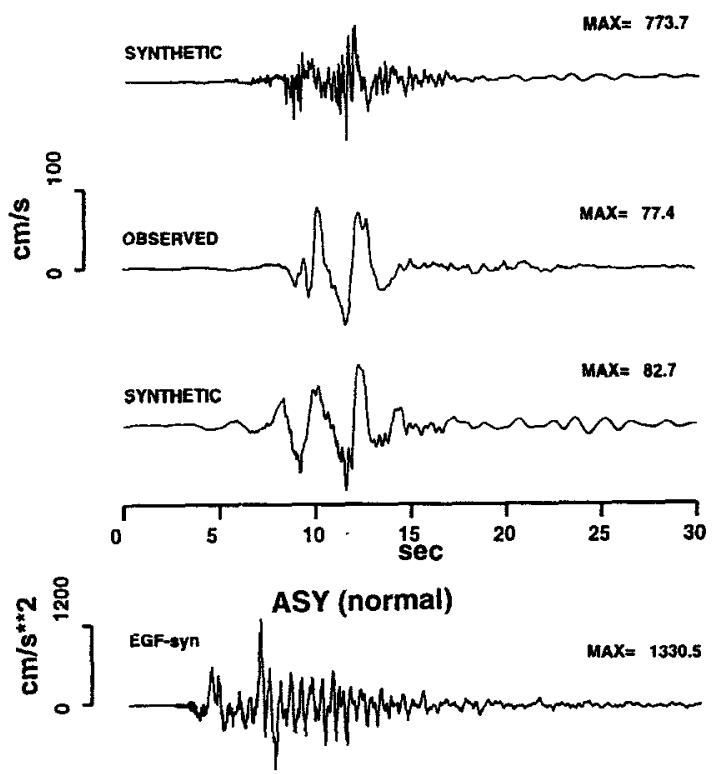

SYNTHETIC

$\operatorname{MAX}=825.5$

量。]
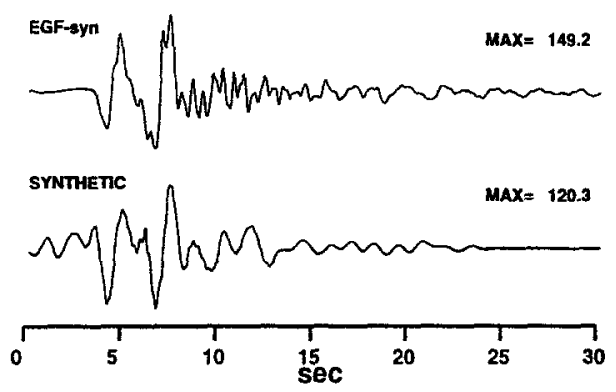

Figure 9. Comparison between the synthetic acceleration and velocity seismogram (faultnormal component) using hybrid Green's functions and the observed ones from the mainshock. The seismogram are bandpass filtered between 0.2 and $10.0 \mathrm{~Hz}$. The synthetic is the result of 1 of 20 simulations that has the peak acceleration amplitude close to the simulated mean value. 
KBU (normal)

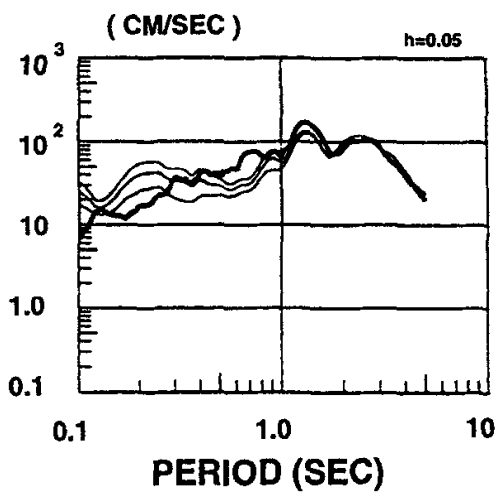

MOT (normal)

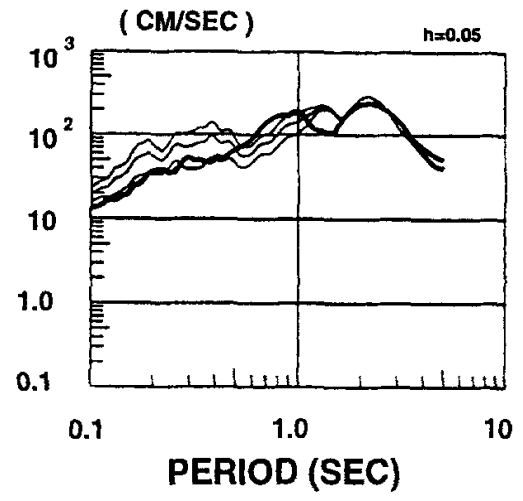

KOB (normal)

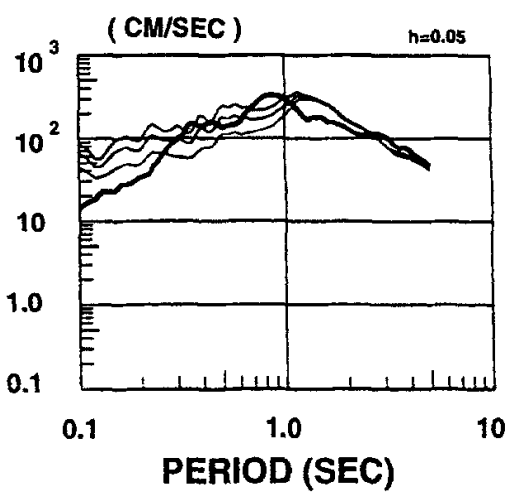

FKI (normal)

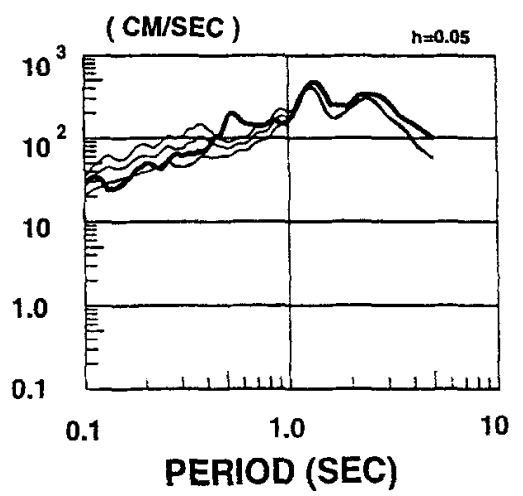

TKT (normal)

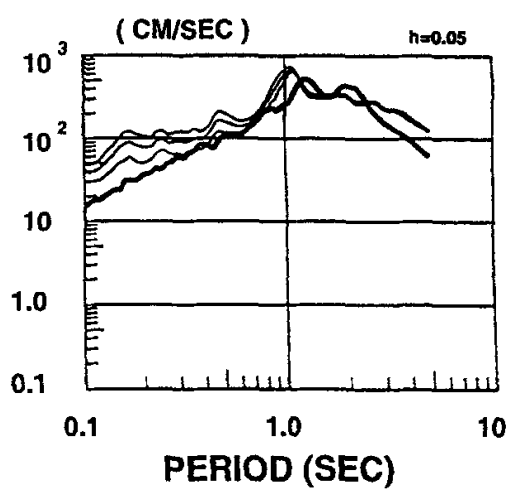

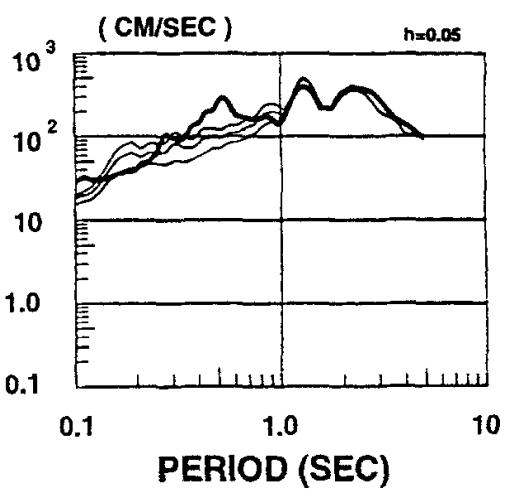

Figure 10. Comparison of the synthetic pseudo-velocity response spectra (the average and the average \pm one standard deviation: light solid line) and the observed one (heavy solid line).

the synthetic seismograms, selected among 20 simulations, that has the peak acceleration amplitude close to the simulated mean value. The standard deviation of the simulated peak amplitude at the considered sites varies from 10 to $20 \%$. A comparison of the pseudo-velocity response spectra is shown in Figure 10. Also shown in this figure is the variation (the mean value and the mean value plus/minus one standard deviation) of the response amplitude in the shortperiod range. At FKI and ASY, where we do not have records of the mainshock ground motions, we compare synthetic seismograms obtained with the HGF and EGF methods. The very good agreement between the synthetics shows that in regions where there is enough information about the deep and shallow geological structure, the HGF method performs as well as the EGF method. The synthetic velocity seismograms are in good agreement with the observed ones in almost all the strong-motion station sites including those in the heavily damaged area. However, at high frequencies, the synthetic ground motions obtained by the HGF method are larger than the observed ones. The same discrepancy was observed when the EGF method was used (Kamae and Irikura, 1998). The fact that the discrepancy exists even at
$\mathrm{KBU}$, which is a rock site, suggests that one factor of the difference in the high frequencies might be caused by the difference in the $f_{\max }$ of the mainshock and the small event. The assumption of linear behavior of soils on which the technique is based might be another factor. Our simulation suggests that during the mainshock, the soft soils at the considered sediment sites behaved nonlinearly. This is in agreement with the conclusion reached by Aguirre and Irikura (1995), who found evidences of nonlinear behavior of the soft-surface sediments at some specific sites in the Kobe city.

\section{Conclusions}

We have proposed a method for simulating broadband ground motions using HGFs. The HGF is produced by combining the finite-difference and stochastic methods that are used to calculate the low- and high-frequency content of the synthetic Green's function, respectively. The method is effective at predicting ground motions from a large earthquake, especially for regions where the absence of smallmagnitude event records precludes the application of the EGF method. We tested the method by comparing the syn- 
thetic with the recorded motion from the 1995 Hyogo-ken Nanbu earthquake $(M w=6.9)$. The comparison suggests that the HGF method is effective at simulating near-source ground motions in a broad-frequency range of engineering interest.

\section{Acknowledgments}

We thank the Committee of Earthquake Observation and Research in the Kansai Area for providing us with the velocity records. We would like to thank T. Kagawa for providing the restored velocity record at MOT station, the Railway Technical Research Institute for the mainshock data at TKT station (Serial Number R-032), and K. Koketsu for the digitalized data for the JMA Intensity 7 area. Encouragements from Prof. Ralf Archuleta are appreciated. We greatly appreciate the useful review by two anonymous reviewers. This study was partially supported by a Grant-in-Aide for Scientific Research, Number 08248111, from the Ministry of Education, Science, Sports, and Culture.

\section{References}

Aguirre, J. and K. Irikura (1995). Preliminary analysis of non-linear site effects at Port island vertical array station during the 1995 Hyogoken Nanbu earthquake, J. Natural Disaster Sci. 16, 49-58.

Boore, D. M. (1983). Stochastic simulation of high-frequency ground motions based on seismological models of the radiated spectra, Bull. Seism. Soc. Am. 73, 1865-1894.

Graves, R. W. (1995). Preliminary analysis of long-period basin response in the Los Angeles region from the 1994 Northridge earthquake, Geophys. Res. Lett. 22, 101-104.

Hartzell, S. H. (1978). Earthquake aftershocks as Green's functions, Geophys. Res. Lett. 5, 1-4.

Hartzell, S., A. Leeds, A. Frankel, and J. Michael (1996). Site response for urban Los Angeles using aftershocks of the Northridge earthquake, Bull. Seism. Soc. Am. 86, S168-S192.

Heaton, T. H., J. F. Hall, D. J. Wald, and M. N. Halling (1995). Response of high-rise and base-isolated buildings to hypocetical Mw7.0 blind thrust earthquake, Science 267, 206-211.

Horikawa, H., K. Hirahara, Y. Umeda, M. Hashimoto, and F. Kusano (1996). Simultaneous inversion of geodetic and strong motion data for the source process of the Hyogo-ken Nanbu, Japan, earthquake, J. Phys. Earth 44, 455-472.

Ide, S. and M. Takeo (1996). Source process of the 1995 Kobe earthquake: determination of spatio-temporal slip distribution by bayesian modeling, Bull. Seism. Soc. Am. 86, 547-566.

Irikura, K. (1986). Prediction of strong acceleration motion using empirical Green's function, Proc. 7th Japan Earthquake Symp., 151-156.

Iwata, T., K. Hatayama, H. Kawase, and K. Irikura (1996). Site amplification of ground motions during aftershocks of the 1995 Hyogo-ken Nanbu earthquake in severely damaged zone--array observation of ground motions at Higashinada ward, Kobe city, Japan, J. Phys. Earth $44,553-562$.

Kagawa, T., K. Irikura, and I. Yokoi (1996). Restoring clipped records of near-field strong ground motion during the 1995 Hyogo-ken Nanbu (Kobe), Japan earthquake, J. Natural Disaster Sci. 18, 43-57.

Kamae, K., P. Y. Bard, and K. Irikura (1998). Prediction of strong ground motion in a EURO-SEISTEST using the empirical Green's function method, J. Seism., in press.

Kamae, K. and K. Irikura (1998). Source model of the 1995 Hyogo-ken Nanbu earthquake and simulation of near-source ground motion, Bull. Seism. Soc. Am. 88, 400-412.

Kawase, H. (1996). The cause of the damage belt in Kobe: "The basin edge effect," constructive interference of the direct $S$ wave with the basin-induced diffracted/rayleigh waves, Seism. Res. Lett. 67, 25-34.

Koketsu, K. (1997). Source process of the mainshock, Joint Report on Great
Hanshin-Awaji earthquake disaster, Vol. 1, Chap. 4, Source process, SSJ, SJCE, AIJ, JGC, and JSME, in print.

Motosaka, M. and M. Nagano (1996). Analysis of ground motion amplification characteristics in Kobe city considering a deep irregular underground structure-interpretation of Heavily damaged belt zone during the 1995 Hyogo-ken nanbu earthquake, J. Phys. Earth 44, $577-590$.

Nakamura, Y., F. Uehara, and H. Inoue (1996). Waveform and its analysis of the 1995 Hyogo-Ken-Nanbu earthquake (II), JR Earthquake Information No. 23d, Railway Technical Research Institute, March (in Japanese).

Pitarka, A. and K. Irikura (1996). Basin structure effects on long period strong motions in the San Fernando valley and the Los Angeles Basin from the 1994 Northridge earthquake and an aftershock, Bull. Seism. Soc. Am. 86, S126-S137.

Pitarka, A., K. Irikura, T. Iwata, and T. Kagawa (1996). Basin structure effects in the Kobe area inferred from the modeling of ground motions from two aftershocks of the January 17, 1995 Hyogoken-nanbu earthquake, $J$. Phys. Earth 44, 563-576.

Pitarka, A., K. Irikura, and T. Iwata (1997). Modeling of ground motion in Higashinada (Kobe) area for an aftershock of the January 17, 1995 Hyogo-ken Nanbu, Japan, earthquake, Geophys. J. Int. 131, 231-239.

Pitarka, A., K. Irikura, T. Iwata, and H. Sekiguchi (1998). Three-dimensional simulation of the near-fault ground motion for the 1995 Hyogoken Nanbu (Kobe), Japan, earthquake, Bull. Seism. Soc. Am. 88, 428440.

Saikia, C. K. (1993). Estimated ground motions in Los Angeles due to Mw $=7$ earthquake on the Elysian thrust fault, Bull. Seism. Soc. Am. 83, 780-810.

Sekiguchi, H., K. Irikura, T. Iwata, Y. Kakehi, and M. Hoshiba (1996). Minute locating of faulting beneath Kobe and the waveform inversion of the source process during the 1995 Hyogo-ken Nanbu, Japan, earthquake using strong ground motion records, J. Phys. Earth 44, 473488.

Tai, M., Y. Iwasaki, and A. Okazaki (1996). A simulation of the 1995 Hyogo-ken nanbu earthquake using stochastic Green's function method in consideration of site specific amplifications and phase characteristics, Proc. 11th WCEE.

Wald, D. J. (1996). Slip history of the 1995 Kobe, Japan, earthquake determined from strong motion, teleseismic, and geodetic data, $J$. Phys. Earth 44, 489-504.

Yoshida, S., K. Koketsu, B. Shibazaki, T. Sagita, T. Kato, and Y. Yoshida (1996). Joint inversion of near- and far-field waveforms and geodetic data for the rupture process of the 1995 Kobe earthquake, J. Phys. Earth 44, 437-454.

Research Reactor Institute

Kyoto University

Noda, Kumatori-cho, Sennan-gun

Osaka, 590-04, Japan

Tel: +81-724-51-2369; Fax: + 81-724-51-2603;

E-mail: kamae@kuca.rri.kyoto-u.ac.jp

(K.K.)

D.P.R.I., Kyoto University

Gokasho, Uji

Kyoto, 611, Japan

Tel/Fax: + 81-774-33-5866; E-mail: irikura@egmdpri01.dpri.kyoto-u.ac.jp

(K.I.)

Woodward-Clyde Federal Services

566 El Dorado Street, Suite 100

Pasadena, California 91101

Tel: 818-449-7650; Fax: 818-449-3536; E-mail: axpitar0@wcc.com

(A.P.)

Manuscript received 10 September 1997. 